Review

\title{
Transferring Landscape Character Assessment from the UK to the Eastern Mediterranean: Challenges and Perspectives
}

\section{Geoffrey Griffiths}

Department of Geography \& Environmental Science, The University of Reading, Reading RG6 6AB, UK; g.h.griffiths@reading.ac.uk; Tel.: +44-118-378-8737

Received: 21 January 2018; Accepted: 5 March 2018; Published: 15 March 2018

\begin{abstract}
Landscape character assessment (LCA) has a significant contribution to make as a spatial framework for the emerging concept of 'multi-functional landscapes', a landscape providing a range of functions, services, and human-derived benefits. The paper reviews the development of LCA in Northwest Europe with a brief description of more recent LCA projects in a Mediterranean context. This is followed by a comparative description of the Living Landscapes approach developed in the UK as applied to Cyprus. The focus is upon the challenges, and limitations, of transferring a method developed in one context to the different physical and cultural setting of the island of Cyprus examining differences in the definition of landscapes, the availability of information on the cultural landscape, the importance of incorporating a strong element of 'time-depth', and the potential of LCA for enhancing land use policy at a time of increased land pressures in the Mediterranean.
\end{abstract}

Keywords: landscape character assessment; multi-functional landscapes; planning; UK; Cyprus

\section{Introduction}

'Landscape' means different things to different people in different contexts and, in some parts of the world, is not even recognized as a concept. However, increasingly we recognize some idea of 'landscape' as a convenient framework within which to plan and manage land resources. For example, the concept of a multi-functional landscape has been current for some time [1,2], with the potential to deliver a range of human benefits at a time of continuing pressure on the rural landscapes of Europe. The concept has been given further credibility and application with the allied concept of ecosystem goods and services [3,4]. However, not only is the concept and definition of landscape contested [5], but the scale at which different ecosystem goods and services function, the many trade-offs between these functions, and the impact of change on the stocks and flows of natural capital [6] are all critical challenges to the application of the ecosystem services paradigm for sustainability. This challenge is made more difficult against a background of very large variability in the landscapes of Europe and, in this context, the Eastern Mediterranean, the product of settlement and cultural patterns over millennia set against a highly variable physical background of climate, soils, geology, and topography. Whilst this variability is acknowledged with many attempts to capture it using a range of mapping methods at a variety of scales [7,8], to date there is only limited literature, including in the geographical literature, that recognises the importance of 'landscape' in the measurement and provision of ecosystem goods and services for human well-being [9] and for physical planning. Thus, Landscape character assessment (LCA) has a potentially key role in this respect bridging the gap between people and landscape, on the one hand, and planning and the need to protect and enhance natural capital on the other. This paper reviews, briefly, the background of LCA in the UK and its recent application in a completely different environment, the island of Cyprus in the Eastern Mediterranean. The principal aim of the paper, however, is to evaluate the extent to which a system developed in one part of Europe 
within the highly-institutionalised framework of the UK (in this example), can be transferred and applied not only to a different physical environment, but also to a country with a very different system of planning and governance. The paper starts with a general introduction to LCA in a pan-European context, followed by more specific comments on the development of LCA in the UK before a description of the application of LCA in Cyprus. Concluding sections focus on the challenges of transferring a method developed in the UK to the different environment of the Eastern Mediterranean.

\section{Landscape character assessment (LCA)}

\subsection{Background}

Without the natural and cultural variability of landscapes being incorporated into a coherent spatial framework, it is unlikely that the potential of the ecosystem services (ES) approach will ever be realised [4]. Effective physical planning for development control and environmental assessment (EA) for example, depends upon the availability of a framework of spatial units that captures differences in 'place'. The system needs to be applicable at a range of scales, transferable between places (countries/regions) and sufficiently practical and understandable for ease of application rather than simply an academic exercise in the recording and mapping of landscapes. This poses very specific challenges and questions: is a universal, widely-applicable system necessary at the European scale or do we continue with the present ad hoc system of national, even sub-national approaches? How is the spatial framework to be constructed: at one end of the debate is the view famously expressed by the European Landscape Convention [10]) that a landscape is, 'an area, perceived by people, whose character is the result of the action and interaction of natural and/or human factors' to apparently objective computer-generated maps based on statistical analysis of spatial input data $[7,8]$.

It is argued that the advantage of adopting an integrated landscape approach is that it incorporates the entire range of meanings that we attribute to landscapes as a "spatial entity; a mental entity; a temporal dimension and as a nexus of nature and culture" [11]. The danger is that the wide meanings attached to landscape prohibit its practical application as a spatial framework at a time when there is an urgent need to plan for resilient landscapes under continuing pressure from threats, such as, climate change, rapid infrastructure development, and changes in agriculture, including land abandonment, particularly prevalent in Mediterranean countries. In the UK, at least, planning has moved from development control towards spatial planning with a new emphasis on sustainability as a core concern [5]. Most counties (and districts) in England have commissioned a Landscape character assessment, many of which are being adopted for use in planning [12]. However, too many of these landscape assessments are visually based, focusing on the visible, natural attributes of the landscape, and often neglecting the cultural aspects that also contribute significantly towards landscape distinctiveness. Without informed map analysis, the assessment simply reflects the visual dimension of the landscape losing the all-important understanding of the contribution of natural factors and cultural processes that help to explain contemporary patterns. Such a visual focus aligns closely with a place-based approach, but stands in sharp contrast to the spatial mapping of landscape units with a strong focus on ecological and environmental objectives that continue to be developed by geographers, landscape ecologists, and historical ecologists. This tension remains real and problematic in the sense that, in some contexts, principally at local and regional scales, it is constraining the development and application of methods for more sustainable planning. Nevertheless, both types of approach are necessary if the system is to be both useable, in the sense of boundaries on a map, and perceptual, in the sense of 'place-based' and recognisable and appreciated by people. Thus, the drawing of borders and the categorisation of areas, e.g., landscape types, are the mapped spatial units that "aim to steer, control and guide how the landscape develops, and is central in understanding what constitutes integration" [13]. This, of course, comes with its own attendant dangers of quasi-objectivity: the perception that a line on a map is 'truth' rather than a spatial simplification or generalization of the diversity of 'land'. By contrast, landscape is often only viewed as 'real' if it is perceived through 
the lens of perception and association that makes different landscapes recognisable and distinctive depending upon association and understanding. As an example of this tension, policies to protect and enhance biodiversity need to be sensitive to the historical forces that have shaped distinctiveness, often overlooked, for example, in current debates about rewilding or reforestation [14].

This failure to agree and develop a common and consistent approach is, therefore, the consequence of many inter-related factors. There is a critical distinction between 'environmental stratification' and LCA that continues to confuse researchers and practitioners alike. The availability of mapped information in digital form, increasingly from the Internet, enables users to adopt statistical, parametric techniques to develop a landscape typology whose properties are critically determined by the user selection of input variables and the processing algorithm [15]. This is useful when the goal is a classification of the whole of Europe, providing semi-automated techniques that rely upon known controls of landscape type (elevation, soil and geology type, land cover) to classify over very large areas. Other good examples include the UK Land Classification System, one of the earliest attempts at environmental stratification as a spatial framework for monitoring countryside change [16]. Many modelling applications benefit from this 'gridded' approach that links well with information derived from satellite imagery and provides a uniform unit area in which to calculate key variables for model input. However, the grid as a spatial framework often fails to capture the 'grain' of the landscape imposing a rigid system onto a resource that is continuously variable, both physically and culturally. Perhaps equally important, people do not resonate with gridded cells-they are not landscapes and, therefore, are meaningless in the context of any sense of identity or sense of place.

By contrast, LCA needs to be more holistic, starting with the construction of a spatial framework that is gradually 'filled' as more detailed information becomes available [17]). The emphasis is on the integration of both natural and cultural information and relies, although not exclusively, on informed understanding of historical and environmental controls on landscape evolution as part of the visual interpretation and integration of mapped sources of data. In this way landscape assessment captures the 'scale' of the landscape, identifying regions of relatively uniform physical and cultural character, often of substantially different geographical extent. There is also the danger of 'repeatability', different interpreters coming to different conclusions to produce a typology and a hierarchy of spatial units that may not be comparable. Nevertheless, the process of mapping is instructive, enabling the interpreter to develop a better understanding of the evolution and inherent character of a landscape.

The availability of data critically determines the type of method adopted. In parts of Europe, where there is a strong tradition of enquiry into historical geography/landscape history and where mapped historical information is often widely available, this provides a strong basis for inclusion of cultural information in LCA.

Finally, there is still confusion about the meaning of some of the terms that are used to describe the landscape characterisation and decision-making process. The temptation to present and reproduce maps without a clear explanation of the methods of classification, the number, scale, and currency of the input variables and the original purpose of the mapping, all contribute towards a generally poor understanding of the process and purpose of LCA. This reduces the value of LCA as a tool for both planning and land management decisions and constrains the intellectual quality of the debate about future development at a time when this is urgently needed.

\subsection{LCA in the Mediterranean}

It is not the case that there has been no interest in the potential of LCA in a Mediterranean context, although a detailed review of what has been achieved and where is beyond the remit of the present paper. Vogiatzakis [18] in particular, has provided a useful summary citing early examples from Spain, Italy (specifically Sardinia), Portugal, France, Slovenia, Malta, and Cyprus. He makes the point that cultural factors have been as significant as natural ones in the development of Mediterranean landscapes [19]. Equally important, Vogiatzakis [18] argues that it is the mapping of the cultural component, particularly in relation to farming systems and associated field patterns, which is missing 
due to the absence of relevant datasets and a tradition of mapping historical landscapes. More recently, a review of LCA in the Eastern Mediterranean [20] identified and mapped a total of 69 landscape types, of which 18 were classified as rare resulting from specific geomorphology or intensive anthropogenic activities. The significance of this work is that it is the first step towards a standard typology applicable across a large part of the Mediterranean providing consistency between, and within, countries and, potentially, facilitating trans-boundary cooperation for the long-term protection and enhancement of important cultural landscapes and areas of high nature conservation importance.

\subsection{The Landscape Map of Cyprus}

The obvious differences in the physical geography of Cyprus, its cultural history, and the contemporary pressures it faces from development, provide a useful contrast to the UK where LCA has been under development and application for more than 20 years. The aim of the Cyprus project was to produce a Landscape character assessment of the whole island based on the Living Landscapes Project (LLP) approach [12]) for spatial planning. There was, therefore, a focus on a 'top-down' mapping approach based on the integration of layers of map information to generate discrete landscape units. This had to be defensible legally in a planning context and, therefore, more likely to be adopted at a time of rapid land-use change and continuing development pressure. These remain urgent issues in Cyprus and it is anticipated that the landscape framework will be used to identify locations that are highly sensitive to change, for example, those areas that have strong ecological, cultural, or visual distinctiveness. In the case of Cyprus, the existing spatial planning system provides the required efficiency, transparency, and citizen participation for the successful integration of landscape considerations into spatial planning, but this needed to be supported by a landscape framework to be an effective decision-making tool. Only with the incorporation of landscape character/quality objectives into development plans can real progress be made in implementing the ELC [10]. However, before spatial plans could be populated with landscape character/quality objectives, and before the planning system could refer to effective landscape policies, a crucial step had to be taken towards the place-based assessment of landscape character and diversity throughout the island. The output of this exercise within the context of the EU-funded MedScapes project [21] was to produce a provisional map of landscape character types (LCTs) for Cyprus at a broad (Level 1) and, later, at the more detailed Level 2 scale. The Level 2 map was subsequently updated with additional information on the cultural components of the landscape from map sources and fieldwork, as part of validation and evaluation.

The hierarchical nature of the Living Landscapes approach [12] enabled the broad patterns of the natural physiography of the island to be mapped based on four attributes: physiography (geology structure and landform); ground type (rock type and soil type); landform (topography from contours); and land cover (Table 1).

Table 1. Living Landscape Project, definitive attributes of landscape description units at Level 1 and Level 2 [11].

\begin{tabular}{ccc}
\hline & Regional Level 1 (1:250,000) & Sub-regional Level 2 (1:50,000) \\
\hline \multirow{2}{*}{ Natural } & Physiography & $\begin{array}{c}\text { Landform } \\
\text { Geology }\end{array}$ \\
\cline { 2 - 3 } & Ground type & $\begin{array}{c}\text { Geology (rock type) } \\
\text { Soils }\end{array}$ \\
\cline { 2 - 3 } Cultural & Land cover & $\begin{array}{c}\text { Tree cover } \\
\text { Farm type (cover) }\end{array}$ \\
\cline { 2 - 3 } & Settlement & $\begin{array}{c}\text { Settlement } \\
\text { Farm type (structure) }\end{array}$ \\
\hline
\end{tabular}

A series of map overlays at approximately 1:250,000 scale were produced for the whole island derived from digital maps provided by the Cypriot authorities and stored within a GIS (geographical 
information system). Spatial data-sets were obtained from a variety of sources including the Department of Town Planning in Cyprus:

- CORINE Land Cover (http://reports.eea.europa.eu/COR0-landcover/en);

- $\quad$ Cyprus Soil Map (1:250,000 scale);

- $\quad$ Cyprus Geology Map (1:250,000 scale) (Cyprus Geological Survey);

- Cyprus 20 m contours (Cyprus Department of Lands and Surveys); and

- Cyprus Topographic Maps (1:50,000) (Cyprus Department of Lands and Surveys).

By overlaying elevation data (contours) on top of the geological/soils data the island was divided initially into broad physiographic units. These units were then overlaid on the ground type/land cover data and subdivided, where appropriate, to distinguish the ecological character and inherent capability of the land. The spatial units that emerge provide the framework for understanding and mapping the historic pattern of land use and settlement, where this information is available. A total of 21 LCTs were mapped at Level 1 (Figure 1 and Table 2), reflecting the specific natural and cultural aspects of the Cypriot landscape.

From Table 2 it is immediately clear that the derivation of landscape character types at the broad Level 1 scale, is linked to the specific conditions of land cover, settlement and geology/soil types characteristic of Cyprus. Information about historical patterns (e.g., land use, settlement patterns, field size, and shape) are of critical significance for mapping the cultural dimension of landscape character but, unlike the situation in a UK context, were not available for Cyprus and had to be generated separately. However, the availability of 1:50,000 scale topographic maps from 1975 (i.e., before the rapid urbanisation of recent decades) provided the opportunity to interpret and map differences in settlement and field patterns for incorporation into the typology at the next, more detailed level in the hierarchy (Level 2). More than 200 spatial units were mapped at Level 2 (Table 2). This proved to be one of the most challenging aspects of the project and, based on extensive fieldwork, a scheme was developed enabling differences in field patterns to be mapped based on the specific conditions prevalent in Cyprus. This represented a critical variation from the typology developed in a UK context [12], but it is known that differences in field patterns are diagnostic of the often complex interrelationship between historical and natural factors operating across the island.

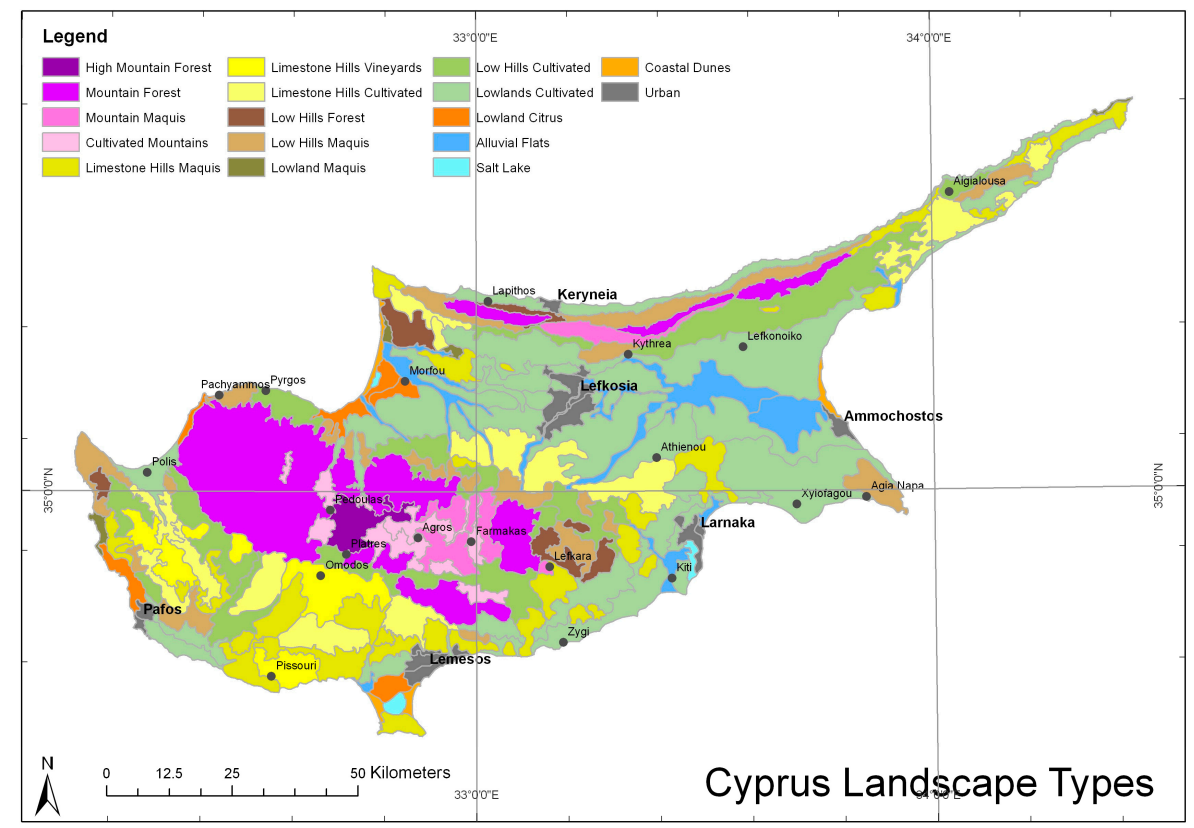

Figure 1. The Level 1 landscape character types for Cyprus. 
Table 2. Landscape character types (LCTs) at Level 1 within the number of Level 2 units in each LCT.

\begin{tabular}{|c|c|c|}
\hline LCT & Number of Level 2 LDUs & Description \\
\hline Coastal dunes & 1 & $\begin{array}{l}\text { Low hills of unconsolidated sand, associated with a strip of bare sand/pebbles, along the coast; unsettled, 'wild' landscape with a covering of } \\
\text { shrubs and other semi-natural vegetation, although patches of bare ground are a feature in places }\end{array}$ \\
\hline Coastal Wetlands & 3 & $\begin{array}{l}\text { Mostly dominated by salt lakes: Landscape with bare land in an undrained natural basin, periodically inundated with salt water and associated } \\
\text { ecosystems, like salt marshes }\end{array}$ \\
\hline Settled coastal hill shrublands & 4 & Undulating hilly topography with covering of shrubs and other semi-natural vegetation; settled landscape lying along the coastline \\
\hline Settled coastal lowland shrublands & 4 & A low-lying landscape near the coast dominated by Mediterranean shrubland; settled \\
\hline Settled cultivated alluvial plains & 11 & Settled, cultivated lowland landscape, mostly low lying, with a gently rolling topography \\
\hline Settled cultivated coastal alluvial plains & 7 & $\begin{array}{l}\text { A flat, settled low-lying landscape, associated with seasonal river channels and their flat plains. Much of the land is cultivated, but patches of } \\
\text { pastoral grazing land are a feature in places }\end{array}$ \\
\hline Settled cultivated coastal hills & 2 & $\begin{array}{l}\text { An undulating, settled and cultivated landscape of low (below } 500 \mathrm{~m} \text { ) hills, with patches of shrubby semi-natural vegetation lying along } \\
\text { the coastline }\end{array}$ \\
\hline Settled cultivated coastal lowlands & 7 & Settled and cultivated lowland landscape near the coast, with discrete rural villages \\
\hline Settled cultivated hills & 20 & An undulating, settled and cultivated landscape of low (below $500 \mathrm{~m}$ ) hills, with patches of shrubby semi-natural vegetation \\
\hline Settled cultivated lowlands & 28 & $\begin{array}{l}\text { A settled and cultivated lowland landscape, with discrete rural villages. Although mostly low lying, with a gently rolling topography, this } \\
\text { landscape also includes a scattering of prominent, small hills }\end{array}$ \\
\hline Settled cultivated mountains & 5 & $\begin{array}{l}\text { A settled and cultivated landscape on higher ground, with an undulating, in places steeply sloping topography, often covered with narrow, stone } \\
\text { walled terraces with mixed cultivation, including a greater or lesser proportion of fruit orchards and vineyards, which thrive on the mineral rich } \\
\text { volcanic soils. Small towns and villages are a characteristic feature of this landscape, often situated along steep valley sides. Houses are stone } \\
\text { built with tiled roofs }\end{array}$ \\
\hline Settled cultivated valleys & 8 & Valleys with relatively medium slopes, characterised by agricultural uses; largely settled \\
\hline Settled forested hills & 2 & A heavily wooded, settled, highland landscape associated with steeply, sloping, high (mostly above $500 \mathrm{~m}$ ) hills \\
\hline Settled forested mountains & 4 & $\begin{array}{l}\text { A heavily wooded, settled, highland landscape associated with steeply/sloping, high (mostly above } 500 \mathrm{~m} \text { ) mountains, found typically on } \\
\text { resistant volcanic (e.g., Troodos) or metamorphic (e.g., Pentadactylos) geology }\end{array}$ \\
\hline Settled forested valleys & 2 & Valleys with natural forest vegetation on the sloping sides of a river with permanent flow; usually settled \\
\hline Settled hill shrublands & 18 & Undulating hilly topography with covering of shrubs and other semi-natural vegetation; settled landscape \\
\hline Settled hill with vineyards & 5 & $\begin{array}{l}\text { An undulating, in places steeply sloping, cultivated limestone landscape, with discrete rural villages and frequent vineyards, often located along } \\
\text { narrow, stone walled terraces }\end{array}$ \\
\hline Settled mountain shrublands & 5 & $\begin{array}{l}\text { Steeply sloping, settled, high (mostly above } 500 \mathrm{~m} \text { ) mountains with a covering of shrubs, typically, the endemic Quercus alnifolia above } 100 \mathrm{~m} \text {, } \\
\text { and other semi-natural vegetation. Prominent rocky outcrops and cliffs are a feature of this landscape in places }\end{array}$ \\
\hline Settled rangeland hills & 2 & A heavily grazed landscape associated with valley hillsides; settled with limited coverage of natural vegetation \\
\hline Unsettled coastal hill shrublands & 4 & Undulating hilly topography with covering of shrubs and other semi-natural vegetation; strongly unsettled landscape lying along the coastline \\
\hline Unsettled coastal lowland shrublands & 4 & A low-lying landscape near the coast dominated by Mediterranean shrubland; unsettled \\
\hline
\end{tabular}




\section{Mapping and Interpretation}

The apparent dichotomy between landscape as diffuse 'scenic space' and landscape as sharply defined, apparently objective lines on a map does not suggest that an adherence to the ELC [10] approach is a pre-requisite for LCA, simply whether a system that relies entirely on the generation of mapped spatial units is also able to accommodate the place-based appreciation of landscape perceived by people as scenic, cultural space. This remains an open question and one of continuing academic debate, but, in a Cypriot context, the rapid rate of development, and the critical need to protect and enhance scenic beauty and ecosystem services, presupposes the existence of a framework of spatial units derived from a commonly understood process, using data from known sources with some degree of quality assurance legally defensible in a planning context.

Data, therefore, becomes a critical issue: its availability in digital format; modernity; type; and scale. Increasingly, the availability of physical data (soils geology, climate; land cover, elevation, etc.) is becoming available from Internet sources. A good example is the frequently-updated land cover mapping available via the CORINE project from the European Environment Agency (EEA). In relation to mapped cultural information, however, the situation is very different. The UK is fortunate in being well-mapped and recorded with, for example, national maps of historical settlement patterns [22]. In many parts of Europe where there is a strong tradition of enquiry into historical geography/landscape history, and where mapped historical information is often widely available, this provides a strong basis for inclusion of cultural information in LCA. Recent work in the UK on historic landscape characterisation [23], and a long tradition of enquiry in historical ecology and landscape history [24-26], has contributed significantly towards the incorporation of cultural information into the landscape character assessment process. This is not a situation that is typical of other parts of Europe and, certainly in an Eastern Mediterranean context, this proved to be the case: much of this information had to be generated from primary map sources to generate proxy information on cultural attributes, e.g., field and settlement patterns. This also raises the important question of transferability: patterns in the landscape that are diagnostic of processes of historical evolution in one context, or country/region, may not be transferrable to another.

Time-Depth

Peoples' perception, understanding, and appreciation of place and its distinctiveness is critically determined by 'time-depth', the visual expression of the cultural forces that have shaped a landscape over time. This is often visually observed, filtered through a complex set of individual experiences and understanding. However, in no other aspect of landscape assessment does the inherent contradiction between subjective appreciation of landscape and the need for 'objective' mapping collide quite so strongly as in the definition and analysis of 'time-depth'. As a result, there is the danger that our understanding of the processes that shape the strong visual patterns in one landscape when transferred to a different historical context, will be misplaced. In a UK context, for example, the distinctive pattern of small, irregular fields so characteristic of the 'ancient countryside' does not translate to Cyprus where small, irregular fields are determined by a separate set of historical processes and topographical influences. This may not matter in a visual sense: the two landscape types show a similarity of pattern. It matters strongly in our understanding and appreciation of landscape and the way in which this affects our ability to measure landscape sensitivity and, ultimately, its capacity to absorb change.

In this context in England, the essential 'time-depth' component of landscape is provided by historic landscape characterisation (HLC), a mapping approach that captures the evolution of a landscape based on archival mapping in a digital GIS environment. The results from HLC are being used to update LCA mapping in England by using the HLC data to identify key historical events, for example, parliamentary enclosure of the medieval open-field system, to validate the cultural attributes of the LCA maps. Typically, the HLC maps express the land cover of a region linked to the dominant historical process that 'produced' that landscape, for example 'anciently-enclosed land', 'industrial land', and 'recently-enclosed land' [27]. The question arises, therefore, whether a similar 
approach could be developed in Cyprus, and the Mediterranean in general, based on existing maps and information. The answer, of course, depends upon the availability of archived information on historical land changes and the expertise to interpret and map them. In Cyprus there is a wealth of information recorded and mapped by successive occupiers, including the Ottomans and British, the cultural layers relating to land ownership, settlement, systems of taxation, etc., that have shaped the landscapes of contemporary Cyprus now changing rapidly in response to the demands of mass tourism.

\section{Planning for Change: Landscape Sensitivity and Capacity}

The contemporary landscape of Cyprus is being shaped by the new 'occupation': mass tourism, contributing to more than $12 \%$ of GDP demanding hotels, communications, and other development associated with membership of the EU and an unusually favourable climate, even by Mediterranean standards. This continues to exert a profound impact on Cypriot landscapes visually, ecologically, and culturally. Whilst the MedScapes project [21] was a first attempt to comply with the European Landscape Convention [10], with a remit focused strictly on mapping, it was clear at the time of the project that the obvious next step would be to apply the framework for evaluation of the sensitivity and capacity of different landscape types.

Against this background of rapid urbanisation the protection of important landscapes depends on the development of a coherent and defensible landscape policy supported by our understanding of which landscapes are highly sensitive to what types of change. However, the use and understanding of landscape sensitivity and capacity remains vague reflecting the context-dependent nature of both terms. Natural England's paper, Techniques and Criteria for Judging Capacity and Sensitivity [28], provides the best guidance however, on the capacity of landscapes to absorb change in relation to measures of their relative sensitivity. Critically, landscape sensitivity is referred to at two different scales: firstly, overall sensitivity, relating to the inherent character of the landscape in question, and, secondly, the specific sensitivity, to a defined proposal (type) of change.

An important objective of the Cyprus landscape project was to develop and apply measures of landscape sensitivity and capacity as part of the development of landscape policy. To this end the more detailed Level 2 mapping based on eight definitive attributes (Table 1) represents a sub-division of the island that captures subtle differences in character in which to determine the ecological, cultural, and visual sensitivity of each landscape unit differently and to evaluate its capacity for absorbing change. This was only possible with extensive field observations of the 'condition' of each landscape unit that, itself, depends on a coherent set of spatial units that can be visited and sampled in a systematic way. Field survey was undertaken in Cyprus to visit every Level 2 LDU to assess their condition in 2015. The data are currently being used in the Akamas peninsula in Cyprus as part of the development of land use policy for this region of high biodiversity and natural beauty given the significant pressures for new development.

Whilst physical planning dominates land use policy in Cyprus currently, this is an island where other pressures are also impacting on the functioning of ecosystems and the long-term integrity of landscapes. Forecasts from regional climate model simulations for the 21st century, for example, highlight the vulnerability of Cyprus to climate change by projecting an increase in maximum temperature of $1.3-1.9^{\circ} \mathrm{C}$ for $2021-2050$ and $3.6-5^{\circ} \mathrm{C}$ for $2071-2100$, and a sharp decrease in rainfall by the end of the century [29]. Rural to urban drift is resulting in extensive agricultural land abandonment in remote areas, in common with many other parts of the Mediterranean. These, and other, impacts are changing the nature of landscapes in ways that are equal in magnitude to any process in the historical past and, as such, are impacting directly on the ecosystem services provided by such landscapes. The concept of ecosystems services [30] has become an important model for linking the functioning of ecosystems to human welfare [31]. Such a link presupposes a spatial framework within which to map and evaluate the provision of ecosystem services at scales ranging from the local to the global [32,33]. In this context a critical requirement is that landscape units, often referred to as 'service providing units' (SPUs) [34] are characterised by defined, recognisable units. Some have argued that we need a 
system that incorporates units that both generate ecosystem services (service providing areas, SPAs) and units that receive those benefits, so-called service benefit areas (SBAs) [35].

However, spatial correlations between ecosystem services and landscape types have often been assumed rather than demonstrated, with the possible notable exception of the paper by Chan et al. [36]. There is a need to develop case studies across a range of landscape types, such as the Cyprus landscape study, to demonstrate the value of LCA as a spatial framework for capturing ecosystem services. This type of framework of functional units also offers the potential to develop useful metrics of the habitats, landscape elements, and land use constraints that significantly influence the generation of ecosystem services and the benefits they offer humanity [35].

\section{Discussion and Conclusions}

Despite the great cultural and natural diversity of Mediterranean landscapes, they are faced with common threats, including climate change, pollution, overgrazing, and tourism development. These problems, combined with a lack of public awareness and political commitment, are hindering the protection and sustainable planning of natural and cultural landscapes. In terms of land use, this absence of 'landscape' from national and regional policy, and the lack of a clear vision for landscape planning, may be a strong disincentive towards the development and implementation of future landscape mapping projects. Thus, future progress will be dependent upon the development and validation of a system of landscape mapping; that is:

- characterised by a strong spatial dimension of mappable units;

- incorporates both natural (soils, geology landform) and cultural dimensions;

- hierarchical, with different nested levels in the system providing richer content at large scales over smaller areas, and vice versa;

- a consistent and robust typology at all scales;

- contains a strong 'time-depth' dimension, capturing the evolution of a landscape;

- 'fits' the existing institutional and political planning framework; and

- transferability between scales and across space, based on consistent data and methods.

The experience from Cyprus indicates that the LCA approach developed in the UK [12] could be successfully transferred to other contexts with a different cultural and natural environment. However, whilst the method proved to be transferrable, the map layers did not, reflecting the absence of mapping of sufficient detail and quality to capture the major historical, 'moments' in the evolution of Cypriot landscapes, and the markedly different physical background and climate of Cyprus compared to the UK.

Nevertheless, despite the LCA approach being available for more than 20 years in Northwest Europe, it remains generally true that land use planning, ecosystem assessment, and environmental assessment (EA) tend not to depend upon a landscape framework. Instead, traditional approaches adopt the water catchment, local authority region, coastal zones, and forest zones as the principal planning unit simply reflecting the reality of existing political and administrative frameworks. Moreover, new approaches and typologies are continually being developed and tested depending upon the purpose of the application: habitat restoration, ecosystem assessment, agri-environment targeting, land-use planning, etc. The result tends to be a sectoral approach that fails to take into account the critical trade-offs between conflicting land use at a time of increasing pressures. The landscape approach, by contrast, provides a robust and consistent framework that is both 'place-based' and applicable across a range of scales and contexts.

Acknowledgments: This work was funded by the EU ENVI MedScapes project, with contributions from the University of Reading, UK. Thanks also to the Laono Foundation, Cyprus, Ioannis Vogiatzakis (Open University, Cyprus), and Phaedon Enotiades, Spatial Planning and Countryside Policy, Town Planning Dept., Cyprus.

Conflicts of Interest: The author declares no conflict of interest. 


\section{References}

1. Naveh, Z. Ten major premises for a holistic conception of multifunctional landscapes. Landsc. Urban Plan. 2001, 57, 269-284. [CrossRef]

2. Fry, G.L.A. Multifunctional landscapes-towards transdisciplinary research. Landsc. Urban Plan. 2001, 57, 159-168. [CrossRef]

3. Millennium Ecosystem Assessment. Ecosystems and Human Well-Being: Synthesis; Island Press: Washington, DC, USA, 2005.

4. De Groot, R.S.; Alkemade, R.; Braat, L.; Hein, L.; Willemen, L. Challenges in integrating the concept of ecosystem services and values in landscape planning, management and decision making. Ecol. Complex. 2010, 7, 260-272. [CrossRef]

5. Selman, P. Planning at the Landscape Scale; Routledge: Abingdon, UK, 2006.

6. Costanza, R.; Daly, H.E. Natural capital and sustainable development. Conserv. Biol. 1992, 6, 37-46. [CrossRef]

7. Wascher, D.M. (Ed.) European Landscape Character Areas-Typologies, Cartography and Indicators for the Assessment of Sustainable Landscapes; Final Project Report as Deliverable from the EU's Accompanying Measure Project European Landscape Character Assessment Initiative (ELCAI), funded under the 5th Framework Programme on Energy, Environment and Sustainable Development (4.2.2); Wageningen University: Wageningen, The Netherlands, 2005; 150p.

8. Mücher, C.A.; Klijn, J.A.; Wascher, D.M.; Schaminée, J.H.J. A new European Landscape Classification (LANMAP): A transparent, flexible and user-oriented methodology to distinguish landscapes. Ecol. Indic. 2010, 10, 87-103. [CrossRef]

9. Potschin, M.B.; Haines-Young, R.H. Ecosystem services. Prog. Phys. Geogr. 2011, 35, 575-594. [CrossRef]

10. Council of Europe. European Landscape Convention, Florence, European Treaty Series—No. 176; Council of Europe: Strasbourg, France, 2000.

11. Tress, B.; Tress, G. Capitalising on multiplicity: A transdisciplinary systems approach to landscape research. Landsc. Urban Plan. 2001, 57, 143-157. [CrossRef]

12. Warnock, S.; Griffiths, G. Landscape characterisation: The living landscapes approach in the UK. Landsc. Res. 2015, 40, 261-278. [CrossRef]

13. Stenseke, M. Integrated landscape management and the complicating issue of temporality. Landsc. Res. 2016, 41, 199-211. [CrossRef]

14. Olwig, K.R. Virtual enclosure, ecosystem services, landscape's character and the 'rewilding' of the commons: The 'Lake District' case. Landsc. Res. 2016, 41, 253-264. [CrossRef]

15. Metzger, M.J.; Bunce, R.G.H.; Jongman, R.H.; Mücher, C.; Watkins, J.W. A climatic stratification of the environment of Europe. Glob. Ecol. Biogeogr. 2005, 14, 549-563. [CrossRef]

16. Bunce, R.G.H.; Barr, C.J.; Clarke, R.T.; Howard, D.C.; Lane, A.M.J. Land Classification for Strategic Ecological Survey. J. Environ. Manag. 1996, 47, 37-60. [CrossRef]

17. Van Eetvelde, V.; Antrop, M. Indicators for assessing changing landscape character of cultural landscapes in Flanders (Belgium). Land Use Policy 2009, 26, 901-910. [CrossRef]

18. Vogiatzakis, I.N. Mediterranean experience and practice in Landscape Character Assessment. Ecol. Mediter. 2011, 37, 17-31.

19. Rackham, O.; Moody, J. The Making of the Cretan Landscape; University Press Manchester: Manchester, UK, 1996.

20. Vogiatzakis, N.I.; Manolaki, P. Investigating the Diversity and Variability of Eastern Mediterranean Landscapes. Land 2017, 6, 71. [CrossRef]

21. Vogiatzakis, I.N.; Manolaki, P.; Trigkas, V. LCA Training and Implementation; Medscapes WP5 Final Report; Open University Cyprus: Lefkosia, Cyprus, 2015.

22. Roberts, B.K.; Wrathmell, S. An Atlas of Rural Settlement in England; English Heritage: London, UK, 2000.

23. Fairclough, G.; Sarlov-Herlin, I.; Swanwick, C. (Eds.) Routledge Handbook of Landscape Character Assessment; Routledge: Abingdon, UK, forthcoming.

24. Peterken, G. Natural Woodland, Ecology E Conservation in Norther Temperate Regions; Cambridge University Press (CUP): Cambridge, UK, 1996.

25. Hoskins, W.G. The Making of the English Landscape; Hodder \& Stoughton: London, UK, 1969.

26. Darby, H.C. A New Historical Geography of England; CUP: Cambridge, UK, 1973. 
27. Turner, S. Historic Landscape Characterisation: A landscape archaeology for research, management and planning. Landsc. Res. 2006, 31, 385-398. [CrossRef]

28. Swanwick, C. Topic Paper 6: Techniques and Criteria for Judging Capacity and Sensitivity; The Countryside Agency and Scottish Natural Heritage: Carys Swanwick, UK, 2004.

29. IPCC. Climate Change 2014: Synthesis Report. Contribution of Working Groups I, II and III to the Fifth Assessment Report of theIntergovernmental Panel on Climate Change; IPCC: Geneva, Switzerland, 2014.

30. Daily, G.C. Nature's Services: Societal Dependence on Natural Ecosystems; Island Press: Washington, DC, USA, 1997.

31. Fisher, B.; Turner, R.K.; Morling, P. Defining and classifying ecosystem services for decision making. Ecol. Econ. 2009, 68, 643-653. [CrossRef]

32. Morse, S.; Vogiatzakis, I.N.; Griffiths, G.H. Space and sustainability: Potential for landscape as a spatial unit for assessing sustainability. Sustain. Dev. 2011, 19, 30-48. [CrossRef]

33. Haines-Young, R.; Martin, J.; Tantram, D. Countryside Quality Counts: Tracking Change in the English Countryside. Constructing an Indicator of Change in Countryside Quality; Report for the Countryside Agency, Defra, English Heritage and English Nature; Nottingham University Consultants Limited: Nottingham, UK, 2004.

34. Luck, G.W.; Harrington, R.; Harrison, P.A.; Kremen, C.; Berry, P.M.; Bugter, R.; Dawson, T.P.; de Bello, F.; Díaz, S.; Feld, C.K.; et al. Quantifying the Contribution of Organisms to the Provision of Ecosystem Services. BioScience 2009, 59, 223-235. [CrossRef]

35. Syrbe, R.-U.; Walz, U. Spatial indicators for the assessment of ecosystem services: Providing, benefiting and connecting areas and landscape metrics. Ecol. Indic. 2012, 21, 80-88. [CrossRef]

36. Chan, K.M.; Shaw, M.R.; Cameron, D.R.; Underwood, E.C.; Daily, G.C. Conservation Planning for Ecosystem Services. PLoS Biol. 2006, 4, e379. [CrossRef] [PubMed]

(C) 2018 by the author. Licensee MDPI, Basel, Switzerland. This article is an open access article distributed under the terms and conditions of the Creative Commons Attribution (CC BY) license (http:/ / creativecommons.org/licenses/by/4.0/). 